Article

\title{
The Influence of the North Atlantic Oscillation Index on Emergency Ambulance Calls for Elevated Arterial Blood Pressure
}

\author{
Jone Vencloviene ${ }^{1, *}$, Agne Braziene ${ }^{1}$, Jurate Zaltauskaite ${ }^{1}$ and Paulius Dobozinskas ${ }^{2}$ \\ 1 Department of Environmental Sciences, Vytautas Magnus University, Donelaicio St. 58, \\ Kaunas LT-44248, Lithuania; braziene.agne@gmail.com (A.B.); jurate.zaltauskaite@vdu.lt (J.Z.) \\ 2 Department of Disaster Medicine, Lithuanian University of Health Sciences, Eiveniu St. 4, \\ Kaunas LT-50028, Lithuania; paulius@smp.lt \\ * Correspondence: j.vencloviene@gmf.vdu.lt; Tel./Fax: +370-650-27090
}

Received: 31 May 2018; Accepted: 26 July 2018; Published: 28 July 2018

\begin{abstract}
The North Atlantic Oscillation (NAO) is the most prominent pattern of atmospheric variability over the middle and high latitudes of the Northern Hemisphere, especially during the cold season. It is found that "weather types" are associated with human health. It is possible that variations in NAO indices (NAOI) had additional impact on human health. We investigated the association between daily emergency ambulance calls (EACs) for exacerbation of essential hypertension and the NAOI by using Poisson regression, adjusting for season, weather variables and exposure to $\mathrm{CO}$, particulate matter and ozone. An increased risk of EACs was associated with NAOI $<-0.5$ (Rate Ratio $(\mathrm{RR})=1.07, p=0.013)$ and NAOI $>0.5(\mathrm{RR}=1.06, p=0.004)$ with a lag of 2 days as compared to $-0.5 \leq \mathrm{NAOI} \leq 0.5$. The impact of NAOI $>0.5$ was stronger during November-March $(\mathrm{RR}=1.10$, lag $=0, p=0.026)$. No significant associations were found between the NAOI and EACs during 8:00-13:59. An elevated risk was associated during 14:00-21:59 with $\mathrm{NAOI}<-0.5(\mathrm{RR}=1.09$, $p=0.003)$ and NAOI $>0.5(\mathrm{RR}=1.09, p=0.019)$ and during 22:00-7:59 with NAOI $<-0.5(\mathrm{RR}=1.12$, $\operatorname{lag}=1, p=0.001$ ). The non-linear associations were found between the NAO and EACs. The different impact of the NAO was found during the periods November-March and April-October. The impact of the NAOI was not identical for different times of the day.
\end{abstract}

Keywords: North Atlantic Oscillation; weather; emergency ambulance calls; exacerbation of essential hypertension

\section{Introduction}

The North Atlantic Oscillation (NAO) is the most prominent and recurrent pattern of atmospheric variability over the middle and high latitudes of the Northern Hemisphere, especially during the cold season months (November-March) [1]. In Northern Europe, during winter, the positive NAO phase was associated with a stronger westerly wind flow, a higher temperature and increased storminess and precipitation, whereas the negative NAO phase leads to weakened westerly wind and a lower temperature and decreased storminess and precipitation [1]. A positive NAO phase is accompanied by a statistically significant increase in the frequency of cyclones and cyclone depths in the North Atlantic between $55^{\circ} \mathrm{N}$ and $75^{\circ} \mathrm{N}$ and in the south-eastern Mediterranean region [2]. As the largest amplitude anomalies in sea level pressure occur during the winter months [3], the highest impact on surface temperature, precipitation and atmospheric pollution indices are also observed during winter months rather than during summer months [1]. The observations during the period 1950-2000 show that during winters with a positive NAO precipitation amount is increased in north-eastern Europe, whereas the precipitation is supressed under the anticyclonic conditions during the summer [4]. 
The same results were observed during the period 1961-2010 in Lithuania [5]. The NAO exerts a strong control on Europe's climate interannual variability and pollution. Oscillations between high and low NAO phases produce large changes in the wind speed and direction over the Atlantic, the heat and moisture transport between the Atlantic and other continents [1]. Thus, NAO influences hemispheric-scale and continent-scale pollution transport [6-8]. The backward trajectories analysis in Lithuania indicates that the predominant origin of air masses is South-western Europe and North Atlantic region $[9,10]$.

It is found that "weather types" (synoptic events categorized by pressure patterns and wind fields) are associated with human health. According to the studies in Italy, significant increases in hospital admissions for myocardial infarction were evident $24 \mathrm{~h}$ after a day characterized by an anticyclonic continental air mass and 6 days after a day characterized by a cyclonic air mass [11]; an increase in ambulatory blood pressure followed a sudden day-to-day change of weather pattern from anticyclonic to cyclonic days [12]. It is possible that variations in NAO indices (NAOI) had additional impact on human health, after adjusting for weather variables and air pollutants. A statistically significant association between mortality from ischemic heart disease and the NAO was found in England in winter time [13] and an association between the incidence of and mortality from acute myocardial infarction and the Arctic Oscillation (AO, which is close to the NAO) indices was found in northern Sweden [14].

In our previous studies, we found the associations between emergency ambulance calls (EACs) for elevated blood pressure (EABP) and weather and space weather variables [15] and exposure to air pollution [16]. The aim of the study was to determine the complex association between daily EACs for EABP occurring in the morning until the early afternoon (8:00-13:59), in the afternoon until the evening (14:00-21:59) and at night until the early morning (22:00-7:59) and NAO indices, adjusting for weather and space weather variables and air pollution.

\section{Methods}

The study was conducted from 1 January 2009 to 30 June 2011. The description of data of EACs is presented in our previous work [15]. The values of daily NAO indices were obtained from the National Oceanic and Atmospheric Administration (NOAA) database ftp:/ /ftp.cpc.ncep.noaa.gov/cwlinks/. We used the NAOI on the day of the call and on two previous days. As the quintiles of the daily NAOI were $-1.01,-0.49,-0.06$ and 0.43 during the study period and the non-linear impact of the NAO is probable, we used the NAOI as categorical variable with categories: $\leq-1,(-1,-0.5]$, $(-0.5,0],(0,0.5]$ and $>0.5$. As confounders, we used the non-linear variables of air temperature $\left(\mathrm{T},{ }^{\circ} \mathrm{C}\right)$, wind speed (WS, kt), barometric pressure (BP, hPA) and relative humidity ( $\left.\mathrm{RH}, \%\right)$, low and active-stormy geomagnetic activity levels, high-speed solar wind (HSSW), daily concentrations of ozone and $\mathrm{PM}_{10}$ and the highest 8-h moving average of $\mathrm{CO}$ concentration. These variables are described in more detail in previous publications $[15,16]$.

\section{Statistical Analysis}

Continuous variables are presented as the mean value (standard error). The univariate associations between NAOI categories and the daily number of EACs for EABP were evaluated by applying ANOVA and Kruskal-Wallis test.

As the numbers of EACs $Y_{t}$ are count variable, we suppose that $Y_{t}$ followed a Poisson distribution with mean $\lambda_{t}$, depending on predictor variables. We applied multivariate Poisson regression to evaluate the association between daily NAOI variables and daily EACs for EABP, which was specified as:

$$
\ln \left(\lambda_{t}\right)=\beta_{0}+\beta X_{t}+\gamma Z_{t}
$$

where $X_{t}$ is a NAOI variable, $\beta$ is vector of coefficients for $X_{t}, Z_{t}$-vectors of confounding factors-years, seasonality, week days, day length, weather, space weather [15] and air pollution variables, as these 
may also affect the daily EACs rate; $\gamma$-is vector of coefficients for $Z_{i}$. The daily incidence of EACs is defined as $\mathrm{E}\left(Y_{t}\right)=\lambda_{t}$. Poisson regression coefficients were interpreted as the difference between the $\log$ of expected counts.

Researchers in the topics of epidemiology and public health have been used the term "the relative risk." It is the ratio of two risks (or, informally, of rates or odds) comparing the risk of disease or death among the exposed to the risk among the unexposed. We could also interpret the Poisson regression coefficients as the log of the rate ratio. This explains the "rate" in incidence rate ratio. In our investigation, it is important for health professionals to evaluate how many times the high or low NAOI value increases the $\lambda_{i}$ (the daily mean value of EACs) as compared to reference category $(-0.5 \leq \mathrm{NAOI} \leq 0.5)$. Let $X_{i}=1$, when NAOI with a lag of 2 days $>0.5, X_{i}=2$, when NAOI with a lag of 2 days $<-0.5$ and $X_{i}=0$ otherwise. Then $\ln \left(\lambda_{i}\right)=\beta_{0}+\beta_{1}\left(X_{i}=1\right)+\beta_{2}\left(X_{i}=2\right)+\gamma Z_{i}, \ln \left(\lambda_{i} \mid X_{i}=1\right)=$ $\beta_{0}+\beta_{1}\left(X_{i}=1\right)+\gamma Z_{i}, \ln \left(\lambda_{i} \mid X_{i}=0\right)=\beta_{0}+\gamma Z_{i}$ and the ratio of daily incidences when $X_{i}=1$ and $X_{i}=0$ $\left(\lambda_{i} \mid X_{i}=1\right) /\left(\lambda_{i} \mid X_{i}=0\right)=\exp \left(\beta_{1}\right)$ is defined as Rate Ratio (RR). We presented adjusted rate ratios (RRs) in the multivariate Poisson regression model. The RRs are presented with $95 \%$ confidence interval (CI) and p-value. The analysis was performed separately for the number of calls during the whole day, in the morning until the early afternoon, in the afternoon until the evening and at night until the early morning during the colder (November-March) and the warmer (April-October) periods. For a sensitivity analysis, we evaluated the association between EACs for EABP and the NAOI separately for older ( $>65$ years) and younger patients. Statistical analysis was performed using SPSS 19 software.

\section{Results}

There were 17,114 emergency calls for EABP during the 911 days of the study: $26 \%$ of the calls were received in the morning until the early afternoon (8:00-13:59), 44.5\%—in the afternoon (14:00-21:59) and $29.5 \%$ - at night (22:00-7:59); $60.2 \%$ of the patients were older than 65 years. The mean number of EACs during the whole day was 18.8, during the time period of 8:00-13:59 it was 4.9, during the period of 14:00-21:59-8.4 and during the period of 22:00-7:59-5.5 [15]. The mean daily number of EACs for elderly was 11.3 and for younger patients it was 7.5. No significant difference was observed in the distribution of NAOI categories during the colder and the warmer periods. During the colder period, more days of NAOI $<-0.5$ were observed in December and more days of NAOI $>0.5$ in March $(48.7 \%)$. During the warmer period, about $30 \%$ of days of NAOI $<-1$ was in June and $58.4 \%$ of days of NAOI $>0.5$ during the period of April-May (Figure 1).

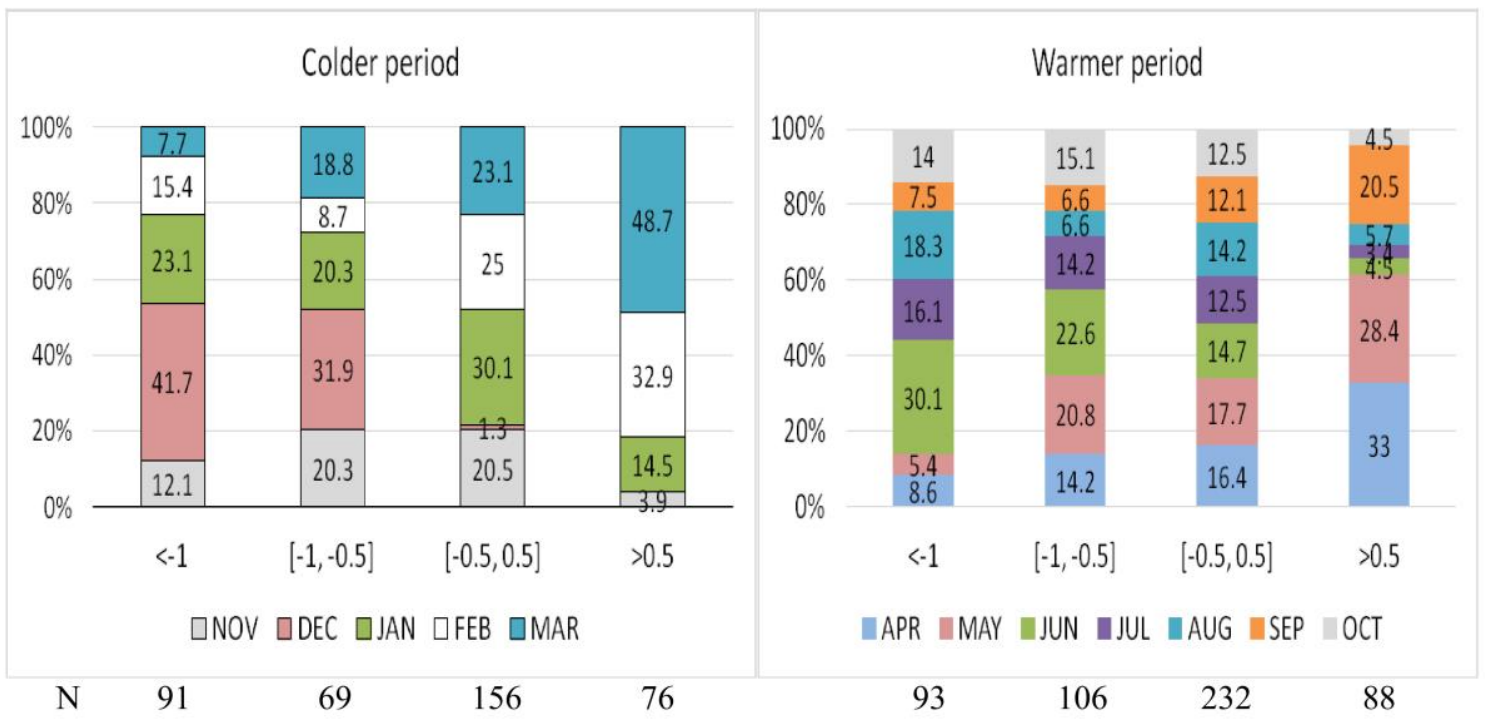

Figure 1. The monthly distribution in the categories of the NAO index during the colder period and the warmer period. 
A non-linear impact of the NAOI on the risk of EACs was observed (Figure 2). During the whole day, an increase in the risk of EACs was associated both with NAOI $<-0.5$ on the day of the call and on two previous days and NAOI $>0.5$ with a lag of 2 days (Table 1). A protective impact of the NAOI between -0.5 and 0 was seen especially on the same and on the previous day (Figure 2). A negative impact of NAOI $<-1$ or NAOI $>0.5$ on the same day was stronger during the period of November-March (Figure 2). No any significant associations between the NAOI and daily EACs were found during the period of April-October).
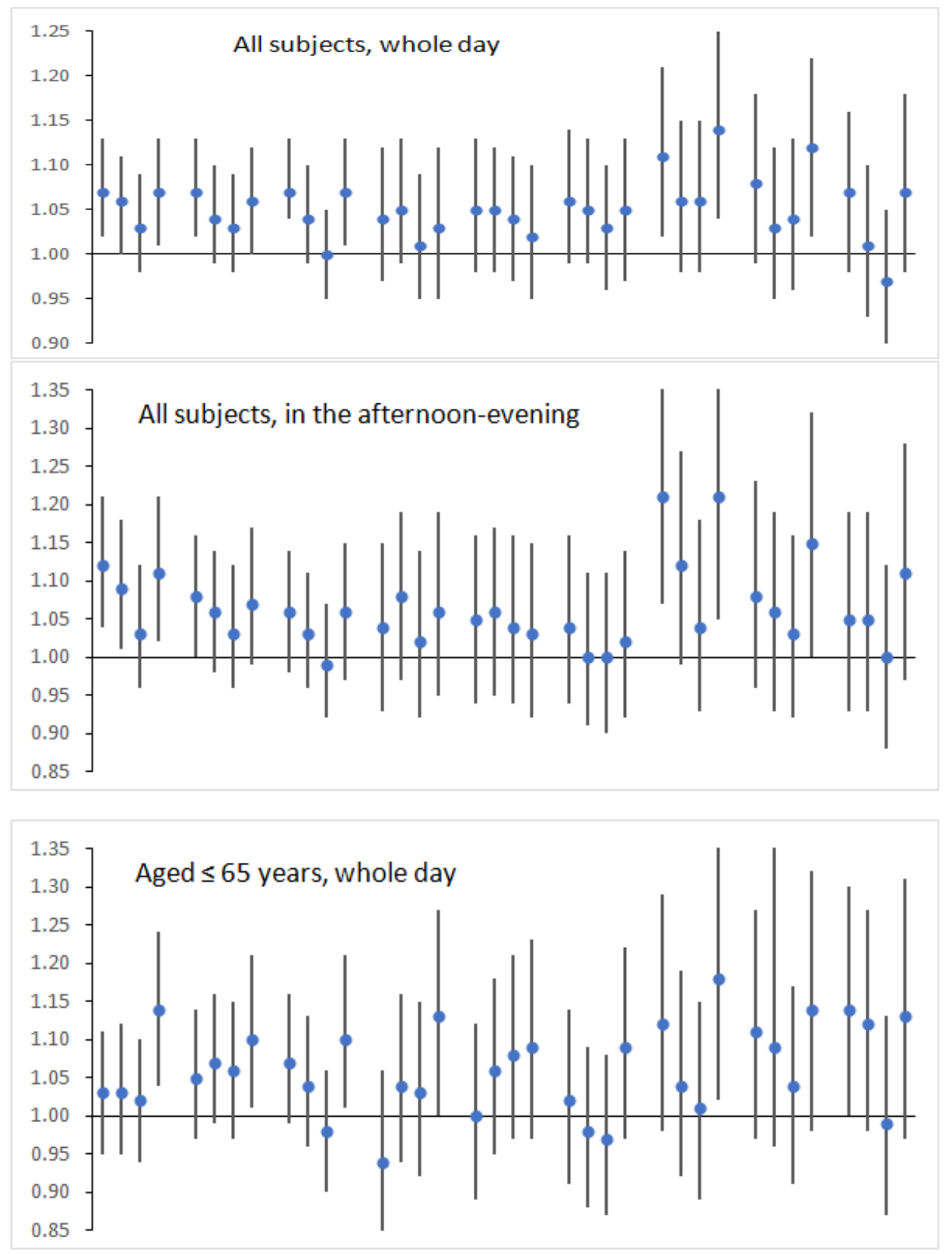

Figure 2. Cont. 


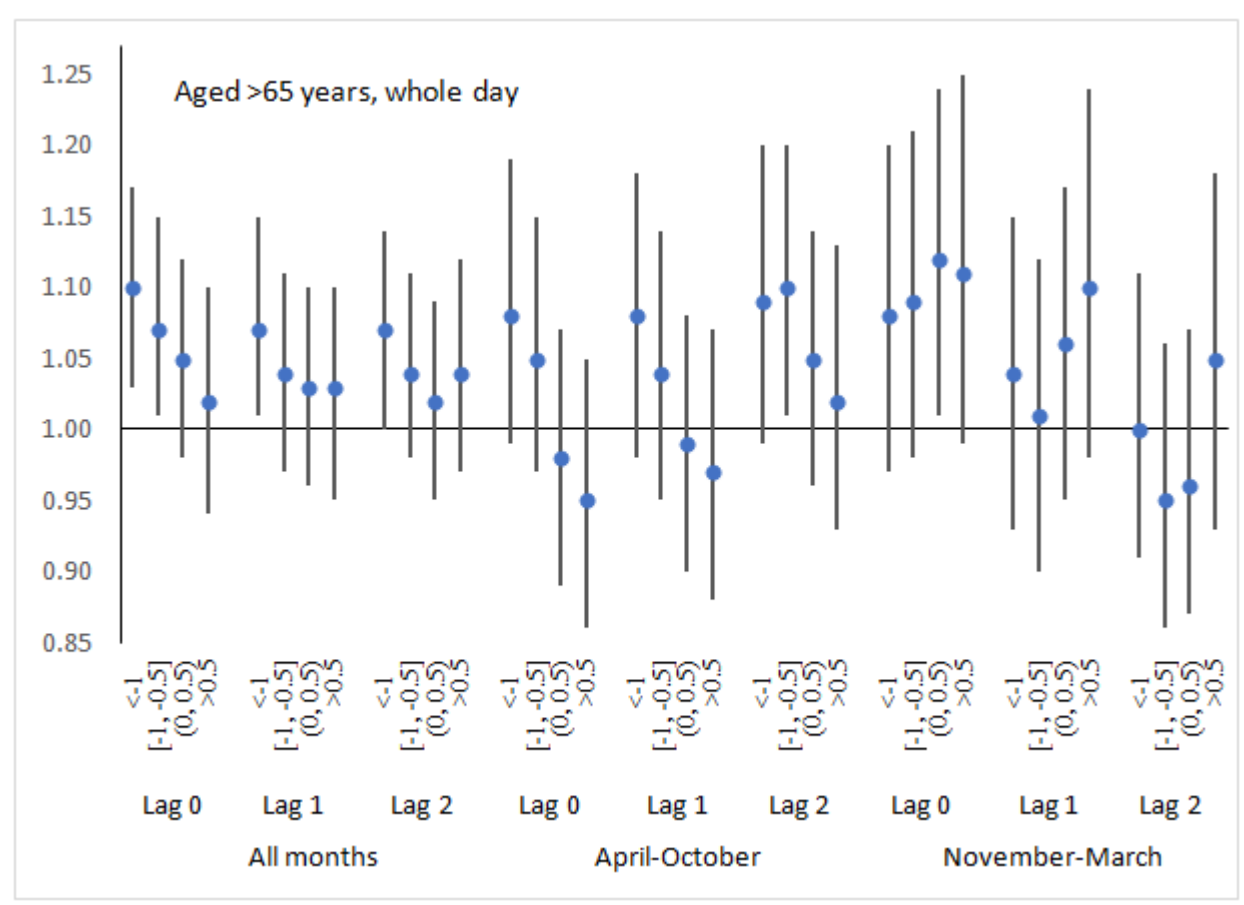

Figure 2. Rate ratios of emergency ambulance calls for elevated arterial blood pressure in the categories of the NAO index (reference category the NAO index between -0.5 and 0 ), adjusting for years, month, the day of the week, day length, weather and space weather variables.

Table 1. Significant associations between the NAO index and daily emergency calls for elevated arterial blood pressure in rate ratios (RR), adjusting for day length, month, years, the day of the week, space weather variable, weather variables and exposure to $\mathrm{CO}, \mathrm{PM}_{10}$ and ozone.

\begin{tabular}{|c|c|c|c|c|c|c|c|c|}
\hline \multirow{3}{*}{$\begin{array}{l}\text { Month } \\
1-12\end{array}$} & \multirow{3}{*}{$\begin{array}{c}\text { Subjects } \\
\text { All whole day }\end{array}$} & \multirow{2}{*}{$\begin{array}{c}\text { NAOI } \\
<-1 \text { vs. }[-1,0.5]\end{array}$} & \multicolumn{2}{|c|}{$\operatorname{RR}(\operatorname{Lag} 0) p$} & \multicolumn{2}{|c|}{$\operatorname{RR}(\operatorname{Lag} 1) p$} & \multicolumn{2}{|c|}{ RR (Lag 2) $p$} \\
\hline & & & 1.05 & 0.033 & 1.05 & 0.034 & 1.06 & 0.007 \\
\hline & & $>0.5$ vs. $[-1,0.5]$ & 1.04 & 0.170 & 1.03 & 0.308 & 1.05 & 0.067 \\
\hline \multirow{2}{*}{$1-12$} & \multirow{2}{*}{ All whole day } & $<-0.5$ vs. $[-0.5,0.5]$ & 1.05 & 0.008 & 1.04 & 0.031 & 1.06 & 0.004 \\
\hline & & $>0.5$ vs. $[-0.5,0.5]$ & 1.05 & 0.054 & 1.04 & 0.130 & 1.07 & 0.013 \\
\hline $4-10$ & All whole day & $<-0.5$ vs. $\geq-0.5$ & 1.04 & 0.129 & 1.04 & 0.168 & 1.04 & 0.098 \\
\hline \multirow{2}{*}{$11-3$} & \multirow{2}{*}{ All whole day } & $<-1$ vs. $[-1,0.5]$ & 1.06 & 0.064 & 1.06 & 0.094 & 1.07 & 0.045 \\
\hline & & $>0.5$ vs. $[-1,0.5]$ & 1.10 & 0.026 & 1.09 & 0.036 & 1.08 & 0.052 \\
\hline \multirow{2}{*}{$1-12$} & \multirow{2}{*}{ All 14:00-21:59 } & $<-0.5$ vs. $[-0.5,0.5]$ & 1.09 & 0.003 & 1.05 & 0.084 & 1.05 & 1.119 \\
\hline & & $>0.5$ vs. $[-0.5,0.5]$ & 1.09 & 0.019 & 1.06 & 0.154 & 1.06 & 0.110 \\
\hline \multirow{2}{*}{$11-3$} & \multirow{2}{*}{ All 14:00-21:59 } & $<-1$ vs. $[-1,0.5]$ & 1.13 & 0.012 & 1.05 & 0.320 & 1.02 & 0.638 \\
\hline & & $>0.5$ vs. $[-1,0.5]$ & 1.15 & 0.023 & 1.11 & 0.081 & 1.10 & 0.144 \\
\hline \multirow{2}{*}{$11-3$} & \multirow{2}{*}{ All 14:00-21:59 } & $<-0.5$ vs. $[-0.5,0.5]$ & 1.14 & 0.008 & 1.06 & 0.282 & 1.05 & 0.287 \\
\hline & & $>0.5$ vs. $[-0.5,0.5]$ & 1.18 & 0.009 & 1.13 & 0.064 & 1.11 & 0.099 \\
\hline $1-12$ & All 22:00-7:59 & $<-0.5$ vs. $\geq-0.5$ & 1.08 & 0.019 & 1.12 & 0.001 & 1.11 & 0.004 \\
\hline $4-10$ & All 22:00-7:59 & $<-0.5$ vs. $\geq-0.5$ & 1.11 & 0.017 & 1.14 & 0.005 & 1.13 & 0.009 \\
\hline $1-12$ & Age $\leq 65$ whole day & $>0.5$ vs. $\leq 0.5$ & 1.12 & 0.004 & 1.03 & 0.157 & 1.09 & 0.026 \\
\hline $4-10$ & Age $\leq 65$ whole day & $>0.5$ vs. $\leq 0.5$ & 1.11 & 0.042 & 1.04 & 0.455 & 1.09 & 0.076 \\
\hline $4-10$ & Age $\leq 65$ whole day & $\mathrm{NAOI}^{\mathrm{a}}$ & 1.06 & 0.017 & 1.05 & 0.059 & 1.03 & 0.243 \\
\hline \multirow{2}{*}{$11-3$} & \multirow{2}{*}{ Age $\leq 65$ whole day } & $<-0.5$ vs. $[-0.5,0.5]$ & 1.06 & 0.265 & 1.06 & 0.232 & 1.11 & 0.029 \\
\hline & & $>0.5$ vs. $[-0.5,0.5]$ & 1.13 & 0.024 & 1.10 & 0.088 & 1.11 & 0.064 \\
\hline $1-12$ & Age $>65$ whole day & $<-0.5$ vs. $\geq-0.5$ & 1.06 & 0.010 & 1.04 & 0.105 & 1.04 & 0.103 \\
\hline $4-10$ & Age $>65$ whole day & $<-0.5$ vs. $\geq-0.5$ & 1.08 & 0.013 & 1.07 & 0.048 & 1.08 & 0.030 \\
\hline $4-10$ & Age $>65$ whole day & $\mathrm{NAOI}^{\mathrm{a}}$ & 0.97 & 0.065 & 0.97 & 0.111 & 0.97 & 0.152 \\
\hline
\end{tabular}


No significant associations were found between the NAO index and EACs for EABP during the period of 8:00-13:59. In the afternoon-evening, a significant impact of a lower and a higher NAOI was observed only on the day of the call. The stronger impact was observed during the colder months (Figure 2, Table 1). At night until early morning, only the negative NAO (NAOI $<-0.5$ ) was associated with an increased number of EACs; the stronger impact was observed during the period of April-October (Figure 2).

For subjects, aged $\leq 65$ years, during the period of April-October, a higher NAOI $(>0.5)$ was associated with an increased risk of EACs. Also, a positive association between the daily NAOI and the daily EACs was found (Table 1). During the colder period, the risk of EACs was associated both with a lower and a higher NAOI (Table 1). For the elderly subjects, during the period of April-October, an increased risk of EACs was associated with a negative NAO (NAOI $<-0.5)$. Also, the association between the NAOI and the risk of EACs tended to be negative ( $R R=0.97, p=0.065$ on the same day) (Table 1).

For sensitivity analysis, we randomly divided the sample into five similar size parts and assessed regression coefficients $\beta$ and its standard deviations for NAOI $>0.5$ and NAOI $<-0.5$ with a lag of 2 days. After, we calculated the mean values of $\beta$ and it confidence interval. For the daily number of EACs, the correspondence values for RRs $(\exp (\beta))$ were, respectively, $1.052(1.0005,1.1061)$ and 1.068 $(1.022,1.115)$.

\section{Discussion}

In our study, a non-linear association between the NAO index and unfavourable health events were determined for the first time. According to the results of our study, an increased risk of the daily EACs for EABP was associated both with a positive $(>0.5)$ and a negative $(<-1$ or $<-0.5)$ values of the NAO index, adjusting the impact of month and weather variables. Such effect may be explained by the impact of the NAO on weather pattern and changes in air pollution level.

Days of NAOI $>0.5$ were found to be associated with an increase in the risk of EAC for all and younger subjects during the colder period. According to the analysis of multiannual data [17], a positive NAO associated with a higher T during the period of November-March. Also, the reverse thermal effects of the positive NAO phase during March of 2009-2011 was observed: BP on days of NAOI $>0.5$ was significantly higher as compared to days of NAOI $\leq 0.5$ and the mean daily air temperature $\left(-0.23^{\circ} \mathrm{C}\right)$ were the lowest during the period of $2000-2012$. The $48.7 \%$ of days of NAOI $>0.5$ during the colder period was in March. March is the first month of spring associated with vitamin deficiency, flu outbreaks and fatigue as well as reduced physical activity after the winter season, therefore at that time, the human body was most vulnerable. Therefore, the impact of the cold on days of NAOI > 0.5 in March may lead to an increased risk of EACs. So, during the studied period, on $61.6 \%$ days mean air temperature was lower than $-1{ }^{\circ} \mathrm{C}$ during the period of January-February. According to the results of our previous studies $[15,18]$, regression models of EACs for EABP for all and aged $\leq 65$ years subjects not included the variable of air temperature lower than $-1{ }^{\circ} \mathrm{C}$; only for the elderly, variables reflecting the impact of the colder air included in the model for the risk of EACs during the whole day and during 14:00-21:59. It is possible that only negative $\mathrm{T}$ concomitant weather pattern on days of the positive NAO are risky for younger subjects.

According to our research, an increase in the risk of EACs was associated with a negative NAO during the colder period, especially with NAOI $<-0.5$ for the period of 14:00-21:59. During colder months of our study, the mean daily T and BP were significantly lower on days of NAOI $<-0.5$ as compared to days of NAOI between -0.5 and 0.5 . It is probable that the complex impact of both lower $\mathrm{T}$ and $\mathrm{BP}$ may be explained by an increase in the risk of EACs during the days of NAOI $<-0.5$ in the colder period.

During the colder period, a negative impact of both a positive and a negative NAOI on human health may be caused by an increased exposure to air pollutant transfer from other regions of Europe and Northern America. During winter months for NAO+ the transport of pollutants from North 
America to Europe is enhanced and the tracer plume is moving towards high latitudes of Europe and reaches it in 8-10 days after tracer emissions [6]. During high NAO phases enhanced northward $\mathrm{NO}_{2}$ and black carbon transport is observed [6]. The differences between NAO+ and NAO- pollutants air concentrations are more expressed in winter. The concentrations of $\mathrm{PM}_{2.5}$ and $\mathrm{PM}_{10}$ during high $\mathrm{NAO}+$ are up to 10 and $20 \mathrm{\mu gm}^{-3}$ respectively higher than during NAO- and represent variations of up to $20-40 \%$ between NAO phases [6]. During winter, a negative NAO associated with a higher concentration of gaseous tracers and water-soluble aerosols emitted from Europe [6,7] in the Baltic countries. The winter-spring peak of aerosol concentration over the north-eastern Europe usually is recorded [9]. Concentrations of nitrogen oxides $\left(\mathrm{NO}\right.$ and $\left.\mathrm{NO}_{2}\right)$ were negatively related to the NAOI in the city of Gothenburg, west Sweden during the winter months for the period 1997-2006 [19]. In our multivariate model, concentrations of ozone, $\mathrm{PM}_{10}$ and $\mathrm{CO}$ were included but we did not adjust for the impact of other pollutants.

According to our results, during the period of April-October, an increase in the risk of EACs was associated with a negative NAO in the elderly and with a higher NAOI in the aged $\leq 65$ years subjects. In mid-latitudes $\sim 55^{\circ} \mathrm{N}, 20-30^{\circ} \mathrm{E}$, during the period of June-September, negative NAO phases are associated with a stronger westerly wind flow, a higher precipitations level, a higher cloudiness and a lower air temperature $[4,8]$. A positive NAO during summer associated with a lower precipitation level, weaker winds and a higher temperature. During the warmer months, NAOI $<-0.5$ on the previous day was associated with a higher WS and a lower BP during the period of our study. The supressed precipitation amount during the summer leads to higher concentrations of aerosols in the atmosphere. Therefore, positive NAO phases favour increased aerosol concentrations in northern Europe regions during summer [8]. In summer, the region of North Poland and Lithuania is also very affected and the high difference between aerosol concentration for $\mathrm{NAO}+$ and $\mathrm{NAO}-$ are determined. The similar differences were recorded not only to particulate matter but also for salt, dust, $\mathrm{SO}_{4}, \mathrm{NO}_{3}$ and $\mathrm{NH}_{4}$ concentrations [8]. The other meteorological parameters related to the NAO and atmospheric pollution are wind speed, temperature and atmosphere oxidative capacity. During the periods of the weaker winds associated with the $\mathrm{NAO}+$ events favour the increase of particulate matter in polluted regions such as large cities or entire industrial regions. It is probable that the complex of meteorological conditions during days of NAOI $<-0.5$ had an additional negative effect associated with an increase in the risk of EACs in the elderly and an increase in the air pollution level during a positive NAO had a negative impact on the younger subjects. Studies on the associations between physical activity in the elderly and weather conditions in Europe showed that physical activity decreased significantly with increasing wind speed, precipitation and humidity [20], a shorter day length and duration of sunshine, a high precipitation amount and a lower maximum temperature [21,22]. These weather conditions are associated with a negative NAO excluding winter months-therefore, it can be assumed that NAOI $<-0.5$ are associated with fewer physical activity opportunities for the elderly, who are likely to be stressed. This can explain the fact that days of NAOI $<-0.5$ increase the risk of EACs in the elderly during the warmer period. It is probable that the impact of weather pattern was stronger as the impact of air pollutants in the elderly, whereas for younger the impact of weather pattern during a negative NAO was slight.

According to literature, both positive and negative NAO phases are associated with worse cardiovascular outcomes. Messner et al. [14] analysed associations between daily Arctic Oscillation $\mathrm{AO}$ ) indices, which are close to the NAO and the incidence of and mortality from acute myocardial infarction (AMI) in northern Sweden. This study established a negative impact of a positive AO with a lag of 3 days: an increase in the $\mathrm{AO}$ index bringing warmer weather over Scandinavia was associated with an increase in the incidence of and mortality from AMI. Statistically significant inverse associations between the climate index (which represents winters with a strong negative phase of the $\mathrm{NAO}$ ) and the level of IHD mortality were found in England [13].

According to our results, the impact of the NAOI as well as weather variables was not identical for different times of the day. No significant impact of the NAOI was observed in the morning until 
the early afternoon. During this period of the day, the impact of weather pattern was stronger as compared to other periods of the day [15] and perhaps because the additional impact of the NAOI not observed. The stronger impact of NAOI $<-0.5$ and NAOI $>0.5$ was found in the afternoon until the evening, especially during the colder period. It is likely that in the afternoon or several hours before, people were more exposed to environment-a lower air temperature or higher precipitations and cloudiness during the warmer period and a higher pollution levels during NAOI $>0.5$. At night-early in the morning, the increased risk of EACs on days of NAOI $<-0.5$ during the warmer period may be explained by an increased stress after the day with poorer weather conditions-a lower T and BP and a higher precipitations and cloudiness.

\section{Conclusions}

An increased risk of the daily emergency ambulance calls for elevated arterial blood pressure was associated both with a positive $(>0.5)$ and a negative $(<-1$ or $<-0.5)$ values of the NAO index, adjusting the impact of month and weather variables. The different impact of the NAO was found during the periods of November-March and April-October. The impact of the NAO index was not identical for different times of the day. No significant impact of the NAO index was observed during the period of 8:00-13:59. The stronger impact of NAOI $<-0.5$ and NAOI $>0.5$ was found in the afternoon until the evening, especially during the colder period.

Author Contributions: J.V. conceived the idea, performed statistical analyses, interpreted the results and was the lead writer. P.D. was responsible for the medical data and read and approved the final manuscript. J.Z. was responsible for the analysis of NAO and this phenomenon impact on climate and air pollution. A.B. assisted with the writing of the manuscript and revised the manuscript. All authors read and approved the final version of the manuscript.

Funding: This research did not receive any specific grant from funding agencies in the public, commercial, or not-for-profit sectors.

Acknowledgments: We acknowledge the contribution of Kaunas city ambulances involved in the registration of cardiovascular emergency admissions and the formation of the computer database.

Conflicts of Interest: The authors declare no conflict of interest.

\section{References}

1. Hurrell, J.W.; Kushnir, Y.; Ottersen, G.; Visbeck, M. An overview of the North Atlantic Oscillation, in the North Atlantic Oscillation: Climate Significance and Environmental Impact. Geophys. Monogr. Ser. 2003, 134, 279. [CrossRef]

2. Bardin, M.Yu.; Polonsky, A.B. North Atlantic Oscillation and Synoptic Variability in the European-Atlantic Region in Winter. Izv. Atmos. Ocean. Phys. 2005, 41, 127-136.

3. Hurrell, J.W.; Deser, C. North Atlantic climate variability: The role of the North Atlantic Oscillation. J. Mar. Syst. 2010, 79, 231-244. [CrossRef]

4. Blade, I.; Liebmann, B.; Fortuny, D.; Jan van Oldenborgh, G. Observed and simulated impacts of the summer NAO in Europe: Implications for projected drying in the Mediterranean region. Clim. Dyn. 2012, 39, 709-727. [CrossRef]

5. Mickevicius, V.; Bukantis, A. Effects of the North Atlantic Oscillation on Lithuanian climate. Water Manag. Eng. 2013, 42, 5-13. (In Lithuanian)

6. Eckhardt, S.; Stohl, A.; Beirle, S.; Spichtinger, N.; James, P.; Forster, C.; Junker, C.; Wagner, T.; Platt, U.; Jennings, S.G. The North Atlantic Oscillation controls air pollution transport to the Arctic. Atmos. Chem. Phys. 2003, 3, 1769-1778. [CrossRef]

7. Christoudias, T.; Pozzer, A.; Lelieveld, J. Influence of the North Atlantic Oscillation on air pollution transport. Atmos. Chem. Phys. 2012, 12, 869-877. [CrossRef]

8. Jerez, S.; Jimenez-Guerrero, P.; Montávez, J.P.; Trigo, R.M. Impact of the North Atlantic Oscillation on European aerosol ground levels through local processes: A seasonal model-based assessment using fixed anthropogenic emissions. Atmos. Chem. Phys. 2013, 13, 11195-11207. [CrossRef] 
9. Byčenkienė, S.; Ulevičius, V.; Prokopčiuk, N.; Jasinevičienè, D. Observations of the aerosol particle number concentration in the marine boundary layer over the south-eastern Baltic Sea. Oceanologia 2013, 55, 573-597. [CrossRef]

10. Plauškaite, K.; Špirkauskaitè, N.; Byčenkienè, S.; Kecorius, S.; Jasinevičienè, D.; Petelski, T.; Zielinski, T.; Andriejauskienè, J.; Barisevičiūtè, R.; Garbaras, A.; et al. Characterization of aerosol particles over the southern and South-Eastern Baltic Sea. Mar. Chem. 2017, 190, 13-27. [CrossRef]

11. Morabito, M.; Crisci, A.; Grifoni, D.; Orlandini, S.; Cecchi, L.; Bacci, L.; Modesti, P.A.; Gensini, G.F.; Maracchi, G. Winter air-mass-based synoptic climatological approach and hospital admissions for myocardial infarction in Florence, Italy. Environ. Res. 2006, 102, 52-60. [CrossRef] [PubMed]

12. Morabito, M.; Crisci, A.; Orlandini, S.; Maracchi, G.; Gensini, G.F.; Modesti, P.A. A synoptic approach to weather conditions discloses a relationship with ambulatory blood pressure in hypertensives. Am. J. Hypertens. 2008, 21, 748-752. [CrossRef] [PubMed]

13. McGregor, G.R. Winter North Atlantic Oscillation, temperature and ischaemic heart disease mortality in three English counties. Int. J. Biometeorol. 2005, 49, 197-204. [CrossRef] [PubMed]

14. Messner, T.; Lundberg, V.; Wikström, B. The Arctic Oscillation and incidence of acute myocardial infarction. J. Int. Med. 2003, 253, 666-670. [CrossRef]

15. Vencloviene, J.; Braziene, A.; Dobozinskas, P. Short-Term Changes in Weather and Space Weather Conditions and Emergency Ambulance Calls for Elevated Arterial Blood Pressure. Atmosphere 2018, 9, 114. [CrossRef]

16. Vencloviene, J.; Braziene, A.; Dedele, A.; Lopatiene, K.; Dobozinskas, P. Associations of short-term exposure to ambient air pollutants with emergency ambulance calls for the exacerbation of essential arterial hypertension. Int. J. Environ. Health Res. 2017, 27, 509-524. [CrossRef] [PubMed]

17. Bukantis, A.; Bartkeviciene, G. Thermal effects of the North Atlantic Oscillation on the cold period of the year in Lithuania. Clim. Res. 2005, 28, 221-228. [CrossRef]

18. Vencloviene, J.; Babarskiene, R.M.; Dobozinskas, P.; Sakalyte, G.; Lopatiene, K.; Mikelionis, N. Effects of weather and heliophysical conditions on emergency ambulance calls for elevated arterial blood pressure. Int. J. Environ. Res. Public Health 2015, 12, 2622-2638. [CrossRef] [PubMed]

19. Grundstrom, M.; Linderholm, H.W.; Klinberg, J.; Pleijel, H. Urban $\mathrm{NO}_{2}$ and $\mathrm{NO}$ pollution in relation to the North Atlantic Oscillation NAO. Atmos. Environ. 2011, 45, 883-888. [CrossRef]

20. Klenk, J.; Büchele, G.; Rapp, K.; Franke, S.; Peter, R. Walking on sunshine: Effect of weather conditions on physical activity in older people. J. Epidemiol. Community Health 2012, 66, 474-476. [CrossRef] [PubMed]

21. Sumukadas, D.; Witham, M.; Struthers, A.; McMurdo, M. Day length and weather conditions profoundly affect physical activity levels in older functionally impaired people. J. Epidemiol. Community Health 2009, 63, 305-309. [CrossRef] [PubMed]

22. Wu, Y.T.; Luben, R.; Wareham, N.; Griffin, S.; Jones, A.P. Weather, day length and physical activity in older adults: Cross-sectional results from the European Prospective Investigation into Cancer and Nutrition (EPIC) Norfolk Cohort. PLoS ONE 2017, 12, e0177767. [CrossRef] [PubMed]

(C) 2018 by the authors. Licensee MDPI, Basel, Switzerland. This article is an open access article distributed under the terms and conditions of the Creative Commons Attribution (CC BY) license (http://creativecommons.org/licenses/by/4.0/). 